\title{
Pathogenesis and Prevention of Progression of Chronic Kidney Disease
}

\author{
Anil K. Mandal1,2,3 \\ ${ }^{1}$ Putnam Community Medical Center, Palatka, USA \\ ${ }^{2}$ University of Florida, Gainesville, USA \\ ${ }^{3}$ University of North Carolina at Chapel Hill, Chapel Hill, USA \\ Email: amandal@med-spec.com
}

Received 10 August 2015; accepted 8 September 2015; published 11 September 2015

Copyright (C) 2015 by author and Scientific Research Publishing Inc.

This work is licensed under the Creative Commons Attribution International License (CC BY). http://creativecommons.org/licenses/by/4.0/

\section{(c) (i) Open Access}

\section{Abstract}

This treatise of chronic kidney disease (CKD) describes association of hypertension, diabetes and congestive heart failure (CHF) with CKD. CKD is defined by estimated glomerular filtration rate (eGFR) of less than $60 \mathrm{ml} / \mathrm{min}$ for three months or more. CKD is generally irreversible but not necessarily progressive. Thus progression of CKD into end stage renal disease (ESRD) is the concern here and what can be done to reduce the progression of CKD. Exact data of CKD with progression are unavailable but high incidence of ESRD (dialysis) eleven times more in 2011 than in 1980 accordingly to United States (US) Renal Data System is a testimonial to progression of CKD in patients with diabetes, hypertension, CHF and other renal diseases. US Renal Data System reveals that ESRD has soared in parallel with marketing of angiotensin converting enzyme inhibitor (ACEI) and angiotensin receptor blocker (ARB) drugs, providing strong indirect evidence that these drugs are someway instrumental in the progression of CKD into ESRD. These drugs produce acute renal failure which is an independent risk factor for CKD. Thus shift in therapy with enthusiastic use of ACEI/ARB drugs has led to dialysis bonanza throughout the world benefiting the professionals and corporations at the expense of vegetative life of the patients associated with family and societal burdens. The ways to turn the pendulum is to treat diabetes with insulin and hypertension with beta blocker, calcium channel blocker and diuretic therapy, and avoid the use of ACEI/ARB drugs. It is important to understand that diuretic orally, by intravenous boluses or by continuous infusion, is the cornerstone of therapy for CHF, whereas ACEI/ARB drugs markedly impair the efficacy of diuretics by lowering the blood pressure to a very low level thereby reducing renal perfusion. An evidence for that is marked elevation of BUN with comparatively slight increase of serum creatinine. Thus with the approaches stated above, CKD is less likely to progress; hence rate of ESRD is likely to decrease.

\section{Keywords}

Pathogenesis, Prevention, Chronic Kidney Disease 


\section{Hypertension and Chronic Kidney Disease (CKD)}

Classification of normal and different stages of hypertension is presented in Table 1.

CKD: CKD or chronic renal failure is defined as irreversible renal failure which may or may not be progressive depending on circumstances and therapeutic approaches. Scientifically, CKD is defined as the presence of Kidney damage associated with glomerular filtration rate (GFR) of less than $60 \mathrm{ml} / \mathrm{min} / 1.73 \mathrm{~m}^{2}$ for 3 or more months irrespective of cause [2]. Renal function is determined by measurement of serum creatinine and estimated glomerular filtration rate (eGFR). In clinical practice, eGFR has been adopted based on the equation from MDRD formula to determine normal renal function or renal failure with different stages [3]. Ordering basic metabolic panel (BMP) will automatically provide eGFR. Most laboratories indicate eGFR $>60 \mathrm{ml} / \mathrm{min}$ as normal renal function and eGFR $<60 \mathrm{ml} / \mathrm{min}$ as renal failure. There is no consistency in the staging of CKD. However, staging is required for the purpose of billing. For the purpose of simplicity and to satisfy insurance companies, the author uses the following equation.

\begin{tabular}{cc}
\hline CKD Stage 1 & $<60>50 \mathrm{ml} / \mathrm{min}$ \\
CKD Stage 2 & $<50>40 \mathrm{ml} / \mathrm{min}$ \\
CKD Stage 3 & $<40>30 \mathrm{ml} / \mathrm{min}$ \\
CKD Stage 4 & $<30>20 \mathrm{ml} / \mathrm{min}$ \\
CKD Stage 5 & $<20>10 \mathrm{ml} / \mathrm{min}$ \\
CKD Stage 6 or ESRD & $<10 \mathrm{ml} / \mathrm{min}$ \\
\hline
\end{tabular}

Medicare qualification for ESRD (dialysis) is eGFR $<10 \mathrm{ml} / \mathrm{min}$. However, other authors define ESRD as eGFR $<15 \mathrm{ml} / \mathrm{min}$ [4].

Hypertension is a major public health concern in the United States and around the world. Hypertension is common in patients with chronic kidney disease (CKD) and the prevalence of hypertension increases as kidney function deteriorates. Chronic Renal Insufficiency cohort study observed an $80 \%$ prevalence of hypertension, which ranged from $67 \%$ in those with eGFR $>59 \mathrm{ml} / \mathrm{min} / 1.73 \mathrm{~m}^{2}$ to $92 \%$ in those with eGFR $>30 \mathrm{ml} / \mathrm{min} / 1.73$ $\mathrm{m}^{2}[5]$.

The three most common ravaging effects of untreated severe and very severe hypertension are stroke, congestive heart failure (CHF) and renal failure. This is an important message for the patients. On the other hand, patients can be assured that adequate and sustained control of hypertension with antihypertensive drug therapy is virtually protective against stroke and $\mathrm{CHF}$.

However, it is slightly controversial if adequate control of BP will provide complete freedom from CKD and myocardial infarction.

Table 1. Classification of Blood Pressure (BP) in adults* .

\begin{tabular}{ccc}
\hline & Systolic $(\mathrm{mmHg})$ & Diastolic $(\mathrm{mmHg})$ \\
\hline Normal & $<130$ & $<80-89$ \\
High Normal & $<130-139$ & $90-99$ \\
Hypertension ${ }^{* *}$ & & $100-109$ \\
Stage 1 (Mild) & $140-159$ & $110-119$ \\
Stage 2 (Moderate) & $160-179$ & $>120$ \\
Stage 3 (Severe) & $180-209$ & \\
Stage 4 (Very Severe) & $>210$ & \\
\hline
\end{tabular}

*Not taking antihypertensive drug therapy; ${ }^{* *}$ Based on average of two or more visits following an initial screening. Isolated systolic hypertension (ISH) is defined as systolic $\mathrm{BP}>140 \mathrm{mmHg}$ and diastolic $\mathrm{BP}<90 \mathrm{mmHg}[1]$. 
Although uncontrolled severe and very severe hypertension can lead to severe arteriolar nephrosclerosis to necrotizing arteiolitis giving rise to ESRD, but there are instances where history of severe hypertension is questionable, yet severe renal failure or ESRD is evident. To that effect, other causes of ESRD should be considered for examples: glomerular diseases or tubulointerstitial disorders such as gouty nephropathy or myeloma Kidney.

A patient is presented here to exemplify the devastating effect of uncontrolled hypertension. A 25 -year-old African American male has had numerous hospital admissions in Oklahoma City, Oklahoma, USA for investigation and treatment of hypertension. He presented to a medical clinic for the first time with complaint of severe headache for four days duration in November 1972. Physical examination showed blood pressure (BP) 240/140 $\mathrm{mmHg}$ (stage 4 hypertension) and grade 2 (K-W-B) retinopathy. BUN and serum creatinine (ScR) were $27 \mathrm{mg} /$ $\mathrm{dl}$ and $2.3 \mathrm{mg} / \mathrm{dL}$, respectively. A complete work-up for secondary hypertension including renal artery stenosis was negative. A wedge biopsy of one of the kidneys during exploratory laparotomy was obtained and studied using light microscopy (LM), immunofluorescence microscopy (IFM) and transmission electron microscopy (TEM). LM was unremarkable except for slight arteriolar thickening. IFM was negative. TEM study of an arteriole showed necrosis and hyperplasia of smooth muscle cells, small amount of collagen tissue and electrondense deposits. These changes indicated early stage of severe vascular changes in the kidneys. He was treated with antihypertensive therapy; his BP was reduced, headache was aborted and kidney function was improved. However, he was noncompliant and not regularly taking his prescribed BP medication. Thus during routine clinic visits, his BP had always been elevated in excess of 240/140 mmHg. After 36 months he developed sudden onset of exertional dyspnea, paroxysmal nocturnal dyspnea and oliguria and was admitted into a hospital with a diagnosis of CHF. His BP was in the range of $250-260 / 140-150 \mathrm{mmHg}$ and flame shaped hemorrhages were noted on ophthalmoscopic examination giving rise to the clinical diagnosis of malignant hypertension. His renal function was markedly decreased with BUN and Scr levels of $110 \mathrm{mg} / \mathrm{dL}$ and $11.5 \mathrm{mg} / \mathrm{dL}$, respectively. Conservative management failed to control BP and CHF; hence he was placed on maintenance hemodialysis. Despite hemodialysis and antihypertensive therapy, his BP remained elevated. Finally in order to reduce BP, he underwent bilateral nephrectomy, after which BP could be reduced with antihypertensive therapy. He didn't develop stroke. Kidney pathology consisted of necrotizing arteriolitis and occlusive changes which were consistent with clinical diagnosis of malignant hypertension. LM histopathology of the nephrectomy specimen is shown in Figure 1 and Figure 2.

Here is another example that uncontrolled hypertension causes CKD, but progression to ESRD can be delayed with control of hypertension. A 76-year-old highly educated white male having long history of hypertension was treated with antihypertensive drugs, but BP was not under control and developed $\mathrm{CKD}$, hence referred to the author.

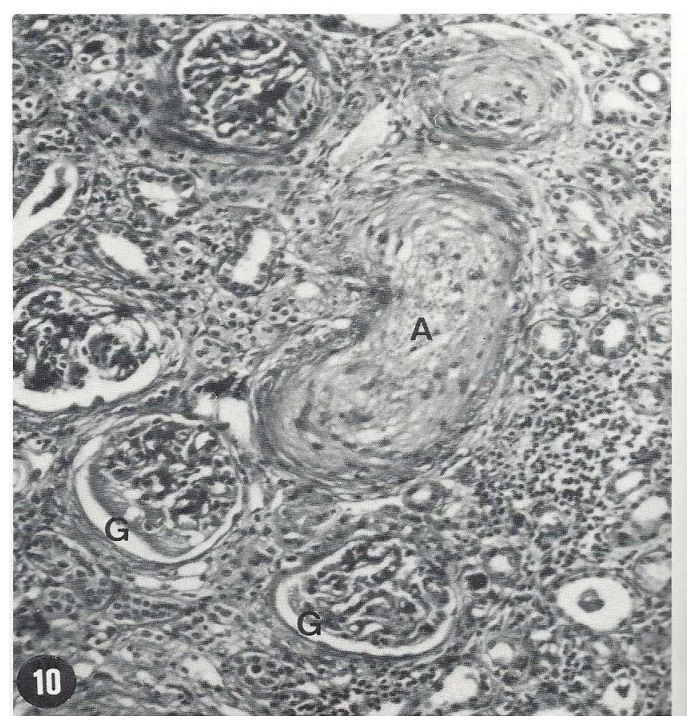

Figure 1. Necrosis of a small artery (A), necrosis of parts of two glomeruli (G), a few atrophic tubules and marked infiltration of the intestitium by monomorphic round cells are seen $(H \& E, 120 \times)$. From the nephrectomy specimen. 


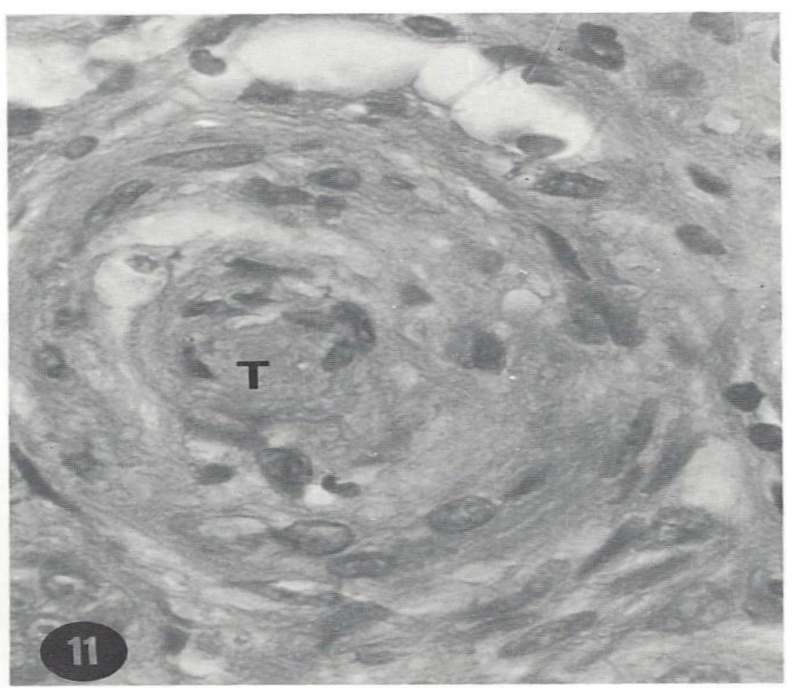

Figure 2. Hyperplasia and necrosis of smooth muscle cells and occlusion of the lumen of a large arteriole by a thrombus $(\mathrm{T})(\mathrm{H} \& \mathrm{E}, 320 \times)$. From the nephrectomy specimen.

Table 2 will reveal his characteristics features between first visit in year 2008 and most recent visit in 2015 .

Renal function has decreased by $0.37 \mathrm{mg} / \mathrm{dL}$ increase of serum creatinine in 7 years with less than $0.1 \mathrm{mg} / \mathrm{dL}$ increase of serum creatinine per year. eGFR decrease is $1 \mathrm{ml}$ per year. He has not developed anemia, a common feature in $\mathrm{CKD}$, not requiring erythropoietic stimulating agent, the most costly therapy. However, he is taking more antihypertensive drugs recently to keep hypertension under control. BP increases with progression of CKD as has been reported previously [5]. He is treated with Sodium bicarbonate and Kayexalate in sorbitol to keep serum bicarbonate and potassium level respectively, under control.

The most remarkable feature in this patient is his astute attention to BP control. He records his BP at home and his home recordings match well with author's office BP readings. Since uncontrolled hypertension as in the first visit is the cause of CKD, tight control of BP has helped to reduce the progression of CKD into ESRD. Sodium bicarbonate therapy to keep metabolic acidosis under control also helps to slow down the progression of CKD [6].

Comments on the relationship between hypertension and chronic renal failure (CKD). These two disparate patients exemplify certain characteristics features: 1) it is evident that stroke or ESRD is more common among African Americans with hypertension. Greater numbers of dialysis population are African Americans. Although the exact cause of rapid progression of CKD in African Americans is not yet elucidated, noncompliance in diet and medication is common. Low education level attests to non-compliance clearly. Most antihypertensive drugs reduce sexual appetite. Lower sense of responsibility combined with failure to satisfy sexual partners compels African Americans to stop antihypertensive therapy. In contrast, the white male presented here is highly motivated and does what needs to be done to stay healthy.

\section{Diabetes and CKD}

\section{A. Diabetes and ESRD}

Diabetes is the most common cause of CKD. As shown in Figure 3, diabetes is the most common cause of ESRD. ESRD means that these patients are treated with either dialysis or renal transplant. Although it is commonly reported that diabetes is the most common cause of ESRD, little information is available to that effect outside of the United States Renal Data System. However, data from India is in agreement with United States Renal data. The Indian CKD registry collected data from 52,273 adult patients who came from South, North, West and East zones. The mean age was $50.1 \pm 14.5$ years with male: female ratio of 70:30. Diabetic nephropathy was the most common cause of CKD (31\%) followed by CKD of undetermined etiology (16\%), chronic glomerulonephritis (14\%) and hypertensive nephrosclerosis (13\%). About 48\% patients had CKD Stage 5; they are younger than those with CKD 3 - 4. Patients in lower income groups had more advanced CKD at presenta- 


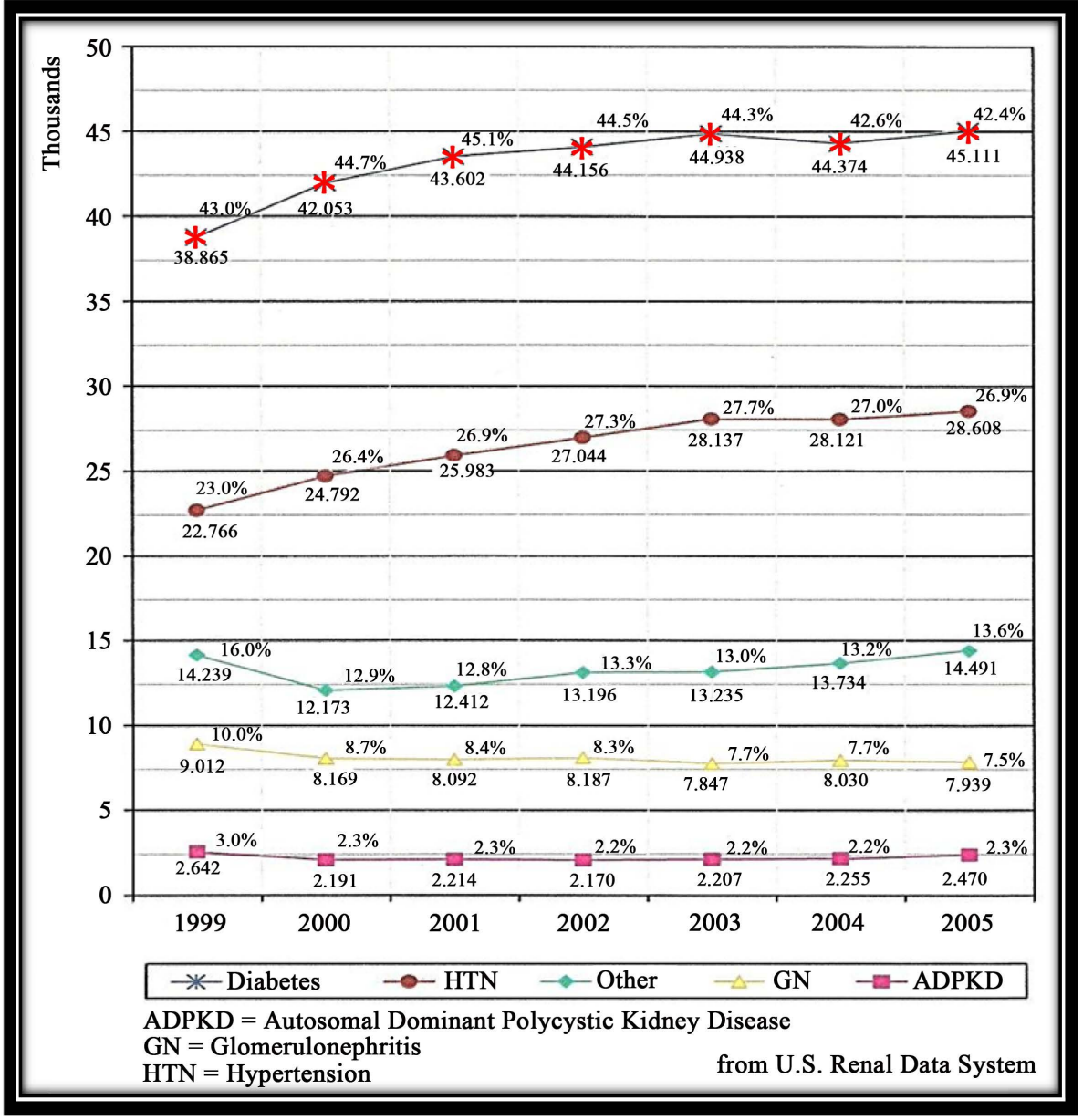

Figure 3. Incidence of ESRD by primary diagnosis.

Table 2. Characteristics features during first and most recent visit. Patient number 2-hypertension 5 years, coronary artery bypass graft 1992.

\begin{tabular}{|c|c|c|}
\hline & First Visit & Recent \\
\hline Month/Year & March 2008 & March 2015 \\
\hline Age (YR) & 70 & 77 \\
\hline Symptoms & None & None \\
\hline Appetite & Good & Good \\
\hline $\mathrm{BP}(\mathrm{mmHg})-\mathrm{S} / \mathrm{D} / \mathrm{MAP}$ & $180 / 110 / 133$ & $130 / 70 / 90$ \\
\hline Edema & None & None \\
\hline BUN/Scr (mg/dl) & $28 / 2.6$ & $30 / 2.97$ \\
\hline eGFR (ml/min) & 26 & 19 \\
\hline $\mathrm{K}(\mathrm{mmol} / \mathrm{L})$ & 4.1 & 4.4 \\
\hline $\mathrm{CO}_{2}(\mathrm{mmol} / \mathrm{L})$ & 29 & 23 \\
\hline $\mathrm{Hb}(\mathrm{g} / \mathrm{dL})$ & 13.1 & 12.5 \\
\hline Medications & $\begin{array}{c}\text { Amlodipine } 5 \mathrm{mg} \text { BID }\left(\text { Norvasc }^{\circledR}\right) \\
\text { Atenolol } 50 \mathrm{mg} \text { daily }\left(\text { Tenormin }{ }^{\mathbb{Q}}\right) \\
\text { Furosemide } 40 \mathrm{mg} \text { every other day } \\
\left(\text { Lasix }^{\mathbb{B}}\right)\end{array}$ & $\begin{array}{l}\text { Amlodipine } 10 \mathrm{mg} \mathrm{AM}, 5 \mathrm{mg} \text { PM } \\
\text { Atenolol } 50 \mathrm{mg} \text { daily } \\
\text { Sodium Bicarbonate } 650 \mathrm{mg} \text { BID } \\
\text { Kayexalate in Sorbitol } 20 \mathrm{ml} \text { BID } \\
\text { Furosemide } 20 \mathrm{mg} \text { daily }\end{array}$ \\
\hline
\end{tabular}

Normal MAP $<95$ mmHg. BP = Blood Pressure; $\mathrm{S}=$ Systolic; $\mathrm{D}=$ Diastolic $;$ MAP = Mean arterial Pressure; Scr $=$ Serum creatinine; eGFR = Estimated Glomerular Filtration rate; $\mathrm{Hb}=$ hemoglobin; $\mathrm{M}=$ Monday; $\mathrm{F}=$ Friday. 
tion. Patients presenting to public sector (Government-run) hospitals are poor, young and more frequently have CKD of unknown etiology [7].

Further studies on CKD risk factors from India show that patients with CKD were older, more likely to be male, had high school diploma, more likely urbanized, overweight or obese, to have diabetes, hypertension and cardiovascular disease than patients without CKD. This study reveals that BP, random hemoglobin and fasting blood glucose correlated significantly with eGFR in the study cohort [8].

Several factors can be considered important underlying the evolution of ESRD in diabetes.

1. Noncompliance in diet and insulin therapy among the patients;

2. Gaps in knowledge concerning diabetes management among the professionals;

3. Overenthusiastic use of angiotensin converting enzyme inhibitor (ACEI) and angiotensin receptor blocking (ARB) drugs to treat microalbuminuria;

4. Little or no attention paid to glycemic control and blaming patients for refusal to take injection of insulin.

\section{Noncompliance in diet control and refusal to take insulin injection for fear of pain}

A 2004-2006 National Health interview survey indicates that only 14\% diabetes patients take insulin, $16 \%$ diabetes patients take insulin and oral medications, $57 \%$ diabetes patients take oral medications and $13 \%$ diabetes patients don't receive any form of therapy. Noncompliance in diet therapy is difficult to estimate, however again noncompliance goes hand in hand with educational and ethnic background.

\section{Gaps in knowledge among the professionals}

There is a prevalent gap of knowledge about the impact of post prandial hyperglycemia ( $2 \mathrm{hPPG})$. It has been reported long time ago that patients with $2 \mathrm{hPPG}>200 \mathrm{mg} / \mathrm{dL}(>11.1 \mathrm{mmol} / \mathrm{L})$ even when fasting glucose was unequivocally normal, are at the highest risk of developing complications [9].

$2 \mathrm{hPPG}$ is well correlated to cardiovascular disorders in many studies. Decode study revealed that the risk for cardiovascular death increases threefold as 2-hour post challenge glucose levels increase from 54 to $199 \mathrm{mg} / \mathrm{dL}$ $(11 \mathrm{mmol} / \mathrm{L})$, although these ranges are all in the non-diabetic range. Data were adjusted for age, gender, weight, systolic BP, cholesterol and smoking during the 11 years of follow-up for the 29714 patients in the diabetes epidemiology: collaborative analysis of diagnostic criteria in Europe (DECODE Study) [10].

\section{The overenthusiastic use of ACEI/ARB drug therapy}

This is a significant factor in the increased incidence of ESRD. Commercialism influencing the prescription pattern of the professionals is the underlying cause of ESRD. In captopril (ACEI) treated diabetes compared to control, the statistical difference was marginal and both groups had hemoglobin A1c over $11 \%$. There were no glucose levels stated in this article and no mention was made how these patients were treated. Since ACEI therapy in diabetes marginally reduced the doubling of serum creatinine level this therapy was reported as renoprotective [11].

The result is explosion of ESRD as shown Table 3. It is evident that ACEI and later on use of ARB drugs have escalated the development of ESRD among the patients with diabetes mellitus.

\section{B. Data from US ESRD Program}

The prescribers order microalbumin to determine the effect of ACEI/ARB therapy. Seldom do they order renal function tests in particular GFR in the form of creatinine clearance. Would they order 24 hour creatinine clearance,

Table 3. ESRD-annual number of Patients with ESRD 1978-2011.

\begin{tabular}{cc}
\hline Year & ESRD-Dialysis (Number of Patients) \\
1978 & 14,000 \\
1986 & 32,000 \\
1991 & ACE entered the market as a renoprotective drug \\
1993 & Article on renoprotective effect \\
1994 & 65,000 \\
1998 & 75,000 \\
2006 & 354,754 \\
2011 & 616,000 \\
\hline
\end{tabular}


they would have been startled to find out for themselves how these drugs reduce proteinuria. Soon it will be found that an internist exactly did that and referred the patient to the author. A 67 years African American female was referred to the author for decreased creatinine clearance. She gave a history of diabetes for 12 years and was treated with glyburide. Her $2 \mathrm{hPPG}$ was always less than $200 \mathrm{mg} / \mathrm{dL}(11.1 \mathrm{mmol} / \mathrm{L})$. However, she was prescribed fosinopril $20 \mathrm{mg}$ P.O daily for proteinuria. The results will be found in Table 4.

Table 4 shows that proteinuria decreased to almost undetectable level to about $5 \mathrm{mg}$. However, proteinuria decreased in parallel with decrease of creatinine clearance (ccl). After discontinuation of fosinopril proteinuria increased so did ccl. Serum creatinine changes are small and can easily be missed as in this patient (Table 4).

Although it is evident that heavy proteinuria is indicative of severe glomerular damage and the lesion is likely to progress, but the progression of the lesion may not manifest clinically. However, ACEI/ARB therapy to reduce proteinuria prompt the appearance of complications, such as metabolic acidosis and hyperkalemia with rapid decrease of kidney function. A patient presented here to exemplify that scenario.

A 54 years white male truck driver has had two hospital admissions in a period of two months. He went to urgent care clinic in December 2013 for routine physical exam and was told that he had very low kidney function and sent to hospital for investigation. He gave history of diabetes for 20 years and was treated with metformin and glyburide. He was not advised to take insulin. He was also taking a combination of Lisinopril (ACEI) and hydrochlorothiazide (HCTZ), for hypertension control. Upon hospital admission his BP was 182/85 $\mathrm{mmHg}$. A basic metabolic panel showed glucose of $94 \mathrm{mg} / \mathrm{dL}$. (5.2 mmol/L), BUN $65 \mathrm{mg} / \mathrm{dl}$, serum creatinine $4.5 \mathrm{mg} / \mathrm{dl}$ with eGFR $15 \mathrm{ml} / \mathrm{min}$. His hemoglobin was $10.8 \mathrm{~g} / \mathrm{dL}$. 24 hour proteinuria was $9962 \mathrm{mg}$ (almost $10 \mathrm{~g}$ ). Percutaneous kidney biopsy was done. He tolerated the procedure well and had no post biopsy bleeding. Lisinopril, HCTZ, metformin and glyburide were discontinued and started on aspart insulin (Novolog ${ }^{\circledR}$ ) and amlodipine $\left(\right.$ Norvasc $^{\circledR}$ ) for glucose and BP control, respectively. He was discharged from the hospital and followed in author's office. Kidney biopsy showed advanced diabetic glomerulopathy on the right and severe tubulointerstial changes on the left (Figure 4).

Due to ESRD, he lost his trucking job and his health insurance. He was prescribed metoprolol, clonidine and chlorthalidone to keep his BP under control and sodium bicarbonate for metabolic acidosis. However, he could not afford to buy the medicines. BP remained elevated and re-admitted to the hospital with stroke and left sided hemiparesis. His $2 \mathrm{hPPG}$ remained higher than $200 \mathrm{mg} / \mathrm{dL}(11.1 \mathrm{mmol} / \mathrm{L})$ at most blood drawn. He was treated with low dose detemir insulin $\left(\right.$ Levemir $\left.^{\mathbb{B}}\right)$.

While in the hospital, he experienced chest pain and showed elevated cardiac enzymes, suggesting myocardial infarction. Cardiac catheterization was recommended but could not be done without hemodialysis support. He was put on maintenance hemodialysis and cardiac catheter study was done which showed extensive coronary artery disease. Thus this patient demonstrates that his diabetes care was poor which permitted him to develop extensive atherosclerosis and ESRD. Should he been treated with paradigm of insulin therapy by Mandal Diabetes Research Foundation, he might have been spared of extensive vascular disease and ESRD, disability or loss of job [12] [13].

Table 4. 67-year-old African American females with 12-year history of diabetes.

\begin{tabular}{|c|c|c|c|}
\hline Date 1999-2006 & 24-h Proteinuria $(\mathrm{mg})$ & 24-h Ccl (ml/min) & Serum Creatinine $(\mathrm{mg} / \mathrm{dl})$ \\
\hline October 17, 1999 & 160 & 125 & 0.8 \\
\hline \multicolumn{4}{|c|}{ Fosinopril $20 \mathrm{mg}$ daily started } \\
\hline Nov. 09,2000 & 88 & 90 & 0.9 \\
\hline Dec. 08,2002 & 142 & 81 & 1.0 \\
\hline Feb. 18, 2004 & 5 & 55 & 1.1 \\
\hline \multicolumn{4}{|c|}{ Fosinopril discontinued. Referred for decreased $\mathrm{Ccl}$} \\
\hline Jul. 15, 2004 & 151 & 96 & 1.0 \\
\hline Jan. 20, 2005 & 417 & 76 & 1.0 \\
\hline Apr. 07, 2005 & 215 & 86 & 0.9 \\
\hline Jun. 08, 2006 & 257 & 70 & 0.7 \\
\hline Dec. 11,2006 & 150 & 80 & 0.96 \\
\hline
\end{tabular}

$\mathrm{CCL}=$ creatinine clearance. 

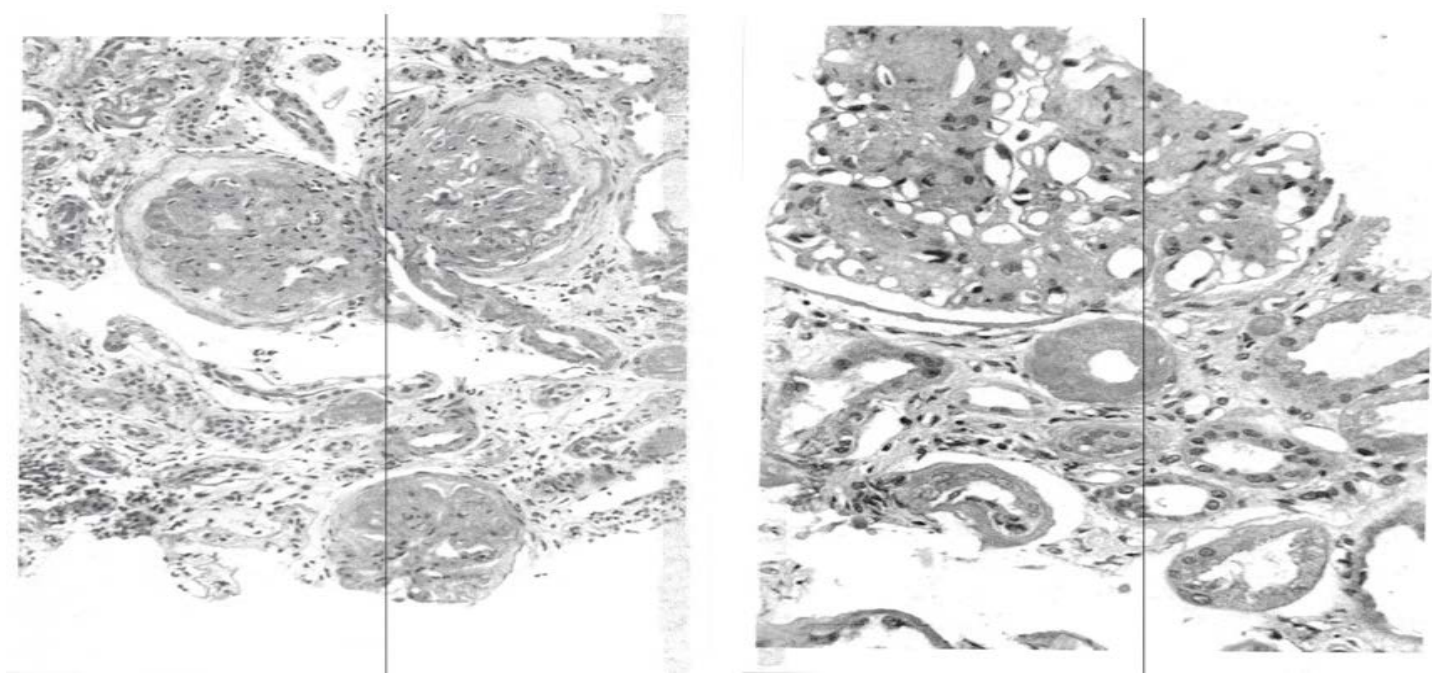

Figure 4. Biopsy results. Left: Three glomeruli are sclerozed; Right: Nodular diabetic glomerulosclerosis Marked. A periglomerular arteriole with hyalinosis is noted. Atrophic tubules are seen.

\section{Congestive Heart Failure and CKD}

Chronic Kidney disease is a common accompaniment of CHF and is independently associated with increased morbidity and mortality $[14]$.

Inhibition of renin-angiotensin-aldosterone system (RAAS) is a conventional approach to the management of patients with severe CHF. Although some objective improvement in cardiac function may be noted, RAAS inhibitor therapy markedly decreases systemic BP which reduces renal perfusion and leads to marked azotemia [15]. Thus pathologically low BP accompanied by progressive decrease in renal function is the hemodynamic basis of inadequate response to diuretic therapy and decreased renal clearance of sodium and water. The result is sustained or recurrent fluid overload which is common place in patients with severe CHF and the main cause of frequent hospitalization for temporary relief of increased shortness of breath [16].

A patient is presented here to demonstrate that scenario. A 65 -year-old white male was seen in consultation by the author for CHF and acute or chronic renal failure. He revealed severe orthopnea, repeatedly begging to help him to sit up at the edge of the bed for breath, generalized edema and ascites which required abdominal paracentesis with removal of 2 liters of clear fluid, and bilateral rales on chest auscultation. All these point toward severe (NYHA class IV) CHF and renal failure with markedly elevated BUN and high BUN/serum creatinine ratio. His BNP was also markedly elevated. Past history included extensive coronary artery disease with coronary artery bypass graft twice in 1990 and 1999, ischemic cardiomyopathy with left ventricular ejection fraction (LVEF) of $10 \%$ and implantable defibrillator. He also gave history of chronic obstructive lung disease.

Significant medication related to his problems was $50 \mathrm{mg}$ losartan $\left(\right.$ cozaar $\left.^{\circledR}\right)$ PO daily. His BP ranged between 80 and $90 \mathrm{~mm}$ systolic. Chest X Ray revealed bilateral pleural effusion and pulmonary edema. Random urine electrolytes showed Na $7 \mathrm{mmol} / \mathrm{L}, \mathrm{K} 59 \mathrm{mmol} / \mathrm{L}$, chloride $26 \mathrm{mmol} / \mathrm{L}$ and creatinine $85.8 \mathrm{mg} / \mathrm{dl}$. These urine electrolytes are consistent with severe CHF with poor renal perfusion. Losartan was discontinued and he was started on bumex infusion ( $24 \mathrm{mg}$ bumetanide in $500 \mathrm{ml}$ of $0.45 \%$ saline solution) at a rate of $21 \mathrm{ml} /$ hour $\times 96$ hours delivering approximately $1 \mathrm{mg}$ bumetanide per hour. Furosemide boluses which he was receiving before was discontinued. His response to bumetanide infusion is shown in Table 5. As urine output increased, his breathing improved in parallel, he was gradually able to lie flat and rest and sleep. $\mathrm{His} \mathrm{HCO}_{3}$ level markedly increased giving rise to alkalemia. He received acetazolamide $500 \mathrm{mg}$ intravenously $\times 3$ doses. His renal function also improved (Table 6) and he was discharged with oral bumetanide twice daily.

Use of RAAS inhibitor drug therapy is a conventional therapy in CHF in order to increase LVEF. However use of RAAS inhibitors is associated with worsening of renal function and fluid overload, repeated hospitalization and high mortality. Bumetanide infusion as already stated is found to produce massive diuresis, symptomatic improvement and even improvement in kidney function [16]. 
Table 5. Response to bumetanide infusion shown in urine output (ml) from Day 1 to Day 6.

\begin{tabular}{ccc}
\hline Urine & Output & Balance (Output-Intake) \\
\hline Day 1 & 1850 & +2042 \\
Day 2 & 8250 & -5793 \\
Day 3 & 10,850 & -9616 \\
Day 4 & Bumetanide infusion reduced to $15 \mathrm{ml} /$ hour & -7040 \\
Day 5 & 8820 & -1722 \\
Day 6 & Bumetanide infusion discontinued & -110 \\
& 3350 & \\
\hline
\end{tabular}

Table 6. Laboratory before and after bumetanide infusion.

\begin{tabular}{ccc}
\hline & Before Infusion & After Infusion \\
\hline $\mathrm{BUN}(\mathrm{mmol} / \mathrm{L})$ & 75 & 58 \\
$\mathrm{Scr}(\mathrm{mmol} / \mathrm{L})$ & 1.48 & 1.38 \\
$\mathrm{eGFR}(\mathrm{mmol} / \mathrm{L})$ & 51 & 58 \\
$\mathrm{Na}(\mathrm{mmol} / \mathrm{L})$ & 133 & 130 \\
$\mathrm{~K}(\mathrm{mmol} / \mathrm{L})$ & 4.3 & 5.5 \\
$\mathrm{CO}_{2}(\mathrm{mmol} / \mathrm{L})$ & 26 & 43 \\
$\mathrm{Albumin}(\mathrm{g} / \mathrm{dL})$ & 2.9 & 3.9 \\
\hline
\end{tabular}

\section{Impact of Commercialism in the Natural History of CKD}

Generally speaking, CKD is indolent and produces no symptoms. The key to the maintenance of indolent state is frequent office visits for instance, every four to six weeks. This model of office visit is designed to evaluate patients with CKD for their well-being; blood pressure control, fluid control and maintenance of acid-base status and hemoglobin. Complete exclusion of ACEI/ARB drugs is needless to emphasize to prevent rocking of renal function downhill, prevent severe metabolic acidosis, hyperkalemia and anemia. Similarly, nonsteroidal drugs as pain killer must be avoided for the same reasons as above. Further, the above drugs cause sodium and water retention and give rise to hypertension and CHF. Control of BP is a difficult issue in some patients despite use of safe drugs such as beta blockers, calcium channel blockers and sympathetic inhibitors. In these difficult cases, low dose diuretic such as 12.5 or $25 \mathrm{mg}$ chlorthalidone every day or every other day is most appropriate to control BP realizing that it may decrease renal function slightly. However, such decrease in renal function doesn't impair well-being or alter acid-base and potassium control [17].

Here is an example to that effect. A 93-year-old African-American female is followed in author's office every four to six weeks for more than 4 years. At her first visit her renal function was low consistent with CKD Stage 5, almost ESRD but has remained essentially unchanged. Despite low renal function her quality of life is good to better over the years and having developed no discernible complication related to low renal function, in particular CHF. The details of her course are presented in Table 7. She gave history of hypertension in the past.

Many changes were made in her therapy throughout her course to keep her BP under control. Prior to the most recent visit her eGFR increased to $15 \mathrm{ml} / \mathrm{min}$ but decreased for resuming chlorthalidone. It is important to note that chlorthalidone is effective in keeping BP under control but lowers Kidney function to an extent. Sodium Polystyrene (Kayexalate) in Sorbitol is continued to keep her serum K under control and sodium bicarbonate prescribed to keep $\mathrm{CO}_{2}$ above $21 \mathrm{mmol} / \mathrm{L}$ Overall patient is asymptomatic, lives a good life with a female companion and shows no evidence of cardiovascular disorders. No hyperkalemia but slight metabolic acidosis is noted because she eats well (Table 8). 
Table 7. History of Hypertension in the past.

\begin{tabular}{cccc}
\hline YEAR & Feb. 2011 & June 2011 & May 2015 \\
Symptoms & Feels throbbing in head & Not feeling well & None \\
BP (sitting) mmHg & $160 / 80$ & $150 / 80$ & $124 / 60$ \\
Appetite & Not Noted & Poor & Better than before eat 3 meals and snacks \\
Edema & No & None & Trace \\
BUN (mg/dl) & 50 & 53 & 64 \\
Scr $(\mathrm{mg} / \mathrm{dL})$ & 3.55 & 3.60 & 4.51 \\
eGFR $(\mathrm{ml} / \mathrm{min})$ & 12 & 12 & 9 \\
Serum $\mathrm{CO}_{2}(\mathrm{as} \mathrm{HCO}) \mathrm{mmol} / \mathrm{L}$ & 30 & 26 & 49 \\
Serum $\mathrm{K}(\mathrm{mmol} / \mathrm{L})$ & 5.1 & 5.0 & 10.9 \\
Hemoglobin $(\mathrm{g} / \mathrm{dl})$ & NA & 11.4 & 4.4 \\
\hline
\end{tabular}

Table 8. Therapy during the course.

\begin{tabular}{|c|c|c|}
\hline Feb 2011 & June 2011 & May 2014 \\
\hline $\begin{array}{l}\text { 1. Atenolol } 50 \mathrm{mg} \text { daily } \\
\text { 2. Losartan (discontinued) } \\
\text { 3. Telmisartan } 80 \mathrm{mg} / \text { daily } \\
\text { 4. Hydralazine } 50 \mathrm{mg} \text { TID } \\
\text { 5. Clonidine } 0.2 \mathrm{mg} \mathrm{PRN} \\
\text { 6. Allopurinol } 100 \mathrm{mg} \text { daily } \\
\text { 7. Alprazolam } 0.25 \mathrm{mg} \text { daily } \\
\text { 8. Lasix was discontinued }\end{array}$ & $\begin{array}{l}\text { 1. Did not take atenolol or clonidine } \\
\text { 2. Metolazone } 2.5 \mathrm{mg} \text { daily discontin- } \\
\text { ued } \\
\text { 3. Metoprolol } 25 \mathrm{mg} \text { daily added }\end{array}$ & $\begin{array}{l}\text { 1. Chlorthalidone } 12.5 \mathrm{mg} / \text { daily } \\
\text { 2. Levothyroxine } 25 \mathrm{mcg} \text { daily } \\
\text { 3. Ferrous Sulfate } 325 \mathrm{mg} \text { daily } \\
\text { 4. Sodium bicarbonate } 650 \mathrm{mg} \times 2 \text { BID } \\
\text { 5. Atenolol } 25 \mathrm{mg} \text { daily } \\
\text { 6. Allopurinol } 100 \mathrm{mg} \text { daily } \\
\text { 7. Megestrol } 40 \mathrm{mg} \text { daily } \\
\text { 8. Amlodipine } 10 \mathrm{mg} \text { twice daily } \\
\text { 9. Kayexalate in Sorbitol } 20 \mathrm{ml} \text { daily }\end{array}$ \\
\hline $\begin{array}{l}\qquad \text { ACTION: } \\
\text { 1. Telmisartan discontinued } \\
\text { 2. Clonidine increased to } 0.1 \mathrm{mg} \text { BID } \\
\text { 3. Kayexalate in Sorbitol } 20 \mathrm{ml} \text { every other day }\end{array}$ & & \\
\hline
\end{tabular}

Given this background, an important question can be asked why so many patients progress into ESRD and become symptomatic warranting dialysis. To that effect, a reasonable answer is concerning the use of ACEI/ ARB drugs. She was symptomatic and not eating well and hyperkalemic. All were due to losartan and later on telmisartan. After discontinuation of ARB her appetite improved in which megestrol may have a role. Thus, in this patient there is no compelling evidence except ESRD to consider dialysis therapy. Even if dialysis is considered what will be the parameters to judge superiority of dialysis therapy vs conservative management [17].

Given the poor outcomes of many old, frail patients with multiple comorbid conditions on dialysis, there is a debate if conservative management as illustrated above, would be more humane than dialysis management [18].

Given this background, why then so many patients are entering into dialysis clinic. United States Renal Data System shows that 116,000 new patients have started renal replacement therapy (RRT) in 2011, and eleven times more patients are treated with RRT in 2011 than in 1980 (Figure 5).

During the past two decades, pendulum has swung from adequate glucose control to excessive and indiscriminate use of ACEI/ARB or combination of both to prevent progression of diabetic nephropathy into ESRD. The medical literature is filled with publications which claim that reduction of proteinuria will delay the progression of diabetic nephropathy into ESRD [19]-[21].

Since ACEI/ARB therapy has not been successful in reducing the rate of diabetes-related ESRD, it is obvious that something is missing in achieving this outcome. [22] By examining the huge body of evidence on the salutary effects of glycemic control in diabetes [23] [24], One can infer that little or no attention to glycemic control is the central missing strategy. 


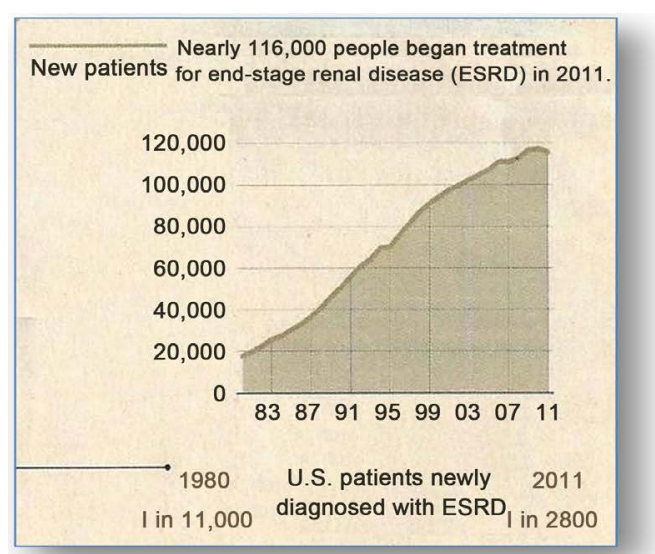

(a)

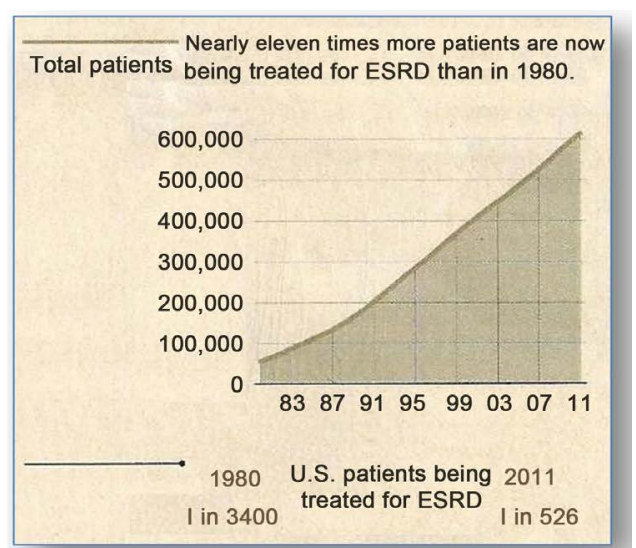

(b)

Figure 5. End stage renal disease in the united states. The apparent reason for the soaring RRT is the commercialism which comprises (a) drug therapy with no effect on glucose control, and (b) shift in therapy for profit.

Further conservative management is an unwealthy endeavor for the professionals; whereas dialysis is far more lucrative for the professionals and corporations [25].

Thus commercialism in nephrology practice looks like this (Figure 6).

\section{Therapeutic Approaches to Attenuate the Progression of CKD into End Stage Renal Disease}

Goal: Preservation of the intact nephron function-intact nephron hypothesis.-Sir Robert Platt

Thus full attention must be paid to the remediable factors which may aggravate renal damage and hence mitigate preservation of intact nephrons in diseased kidneys

Remediable (Modifiable) factors include

1. Nephrotoxic drugs or agents: ACEI/ARB, Amino glycosides, Radio contrast materials;

2. Uncontrolled diabetes;

3. Uncontrolled hypertension;

4. Recurrent urinary tract infection;

5. Unilateral or bilateral urinary tract obstruction;

6. Hypokalemia;

7. Hyperuricemia;

8. Fluid loss from causes such as vomiting or diarrhea;

9. Phosphate therapy for colonoscopy;

10. NSAID-Non steroidal anti-inflammatory drugs.

General Considerations of Therapy

Frequent Office visits (Every 4 to 6 weeks) for intensive check-up of the following [17]

a) Symptoms;

b) Weight;

c) Blood Pressure;

d) Hemoglobin/Hematocrit;

e) Glucose level: Fasting and 2 hour postprandial;

f) Renal function: BUN, CR, eGFR;

g) Electrolytes: $\mathrm{Na}, \mathrm{K}, \mathrm{CO}_{2}$, calcium, phosphorus, albumin and uric acid;

h) Intact PTH;

i) Arterial blood gas for oxygen level and with low $\mathrm{CO}_{2}$ in renal panel, to distinguish between metabolic acidosis and respiratory alkalosis and to determine severity of metabolic acidosis;

j) Electrocardiogram for irregular heart rhythm (for those with metabolic acidosis or hyperkalemia);

k) Review medicines from all doctors in every visit;

1) Discontinue any drug suspected of adverse effect on the kidney. 


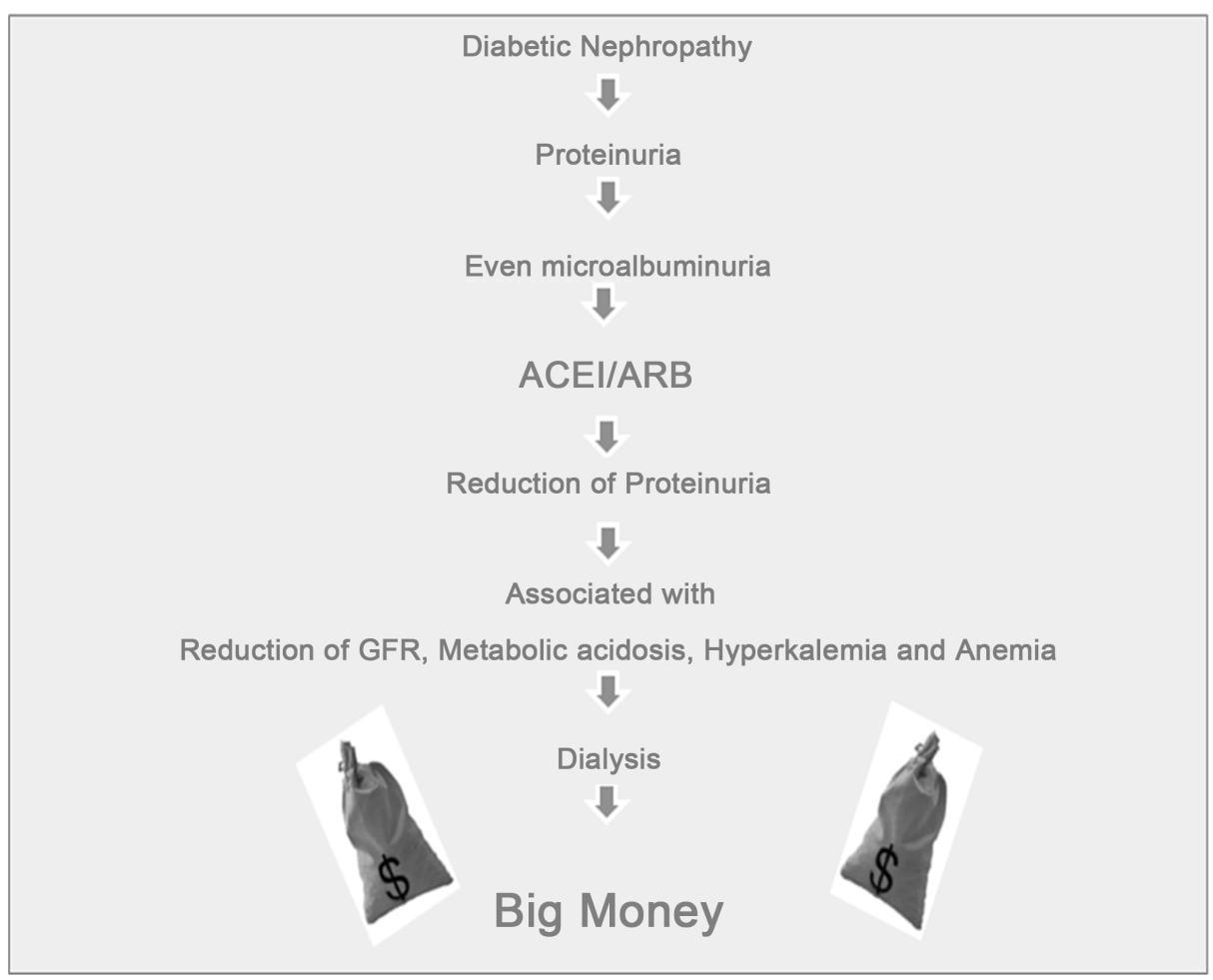

Figure 6. Commercialism in nephrology practice.

\section{Specific Treatment}

1. Maintain adequate fluid volume; replace fluid loss promptly;

2. Keep blood pressure at normal level $(\leq 130 / 70-\mathrm{mmHg})(\mathrm{MAP}<95 \mathrm{mmHg})$;

3. For diabetes, keep blood sugar at near normal level with insulin, but not oral drugs;

4. Prescribe a low protein diet $(50-60 \mathrm{~g})$;

5. Avoid nephrotoxic drugs, such as ACEI/ARB, NSAID, aminoglycoside antibiotics;

6. Use low dose diuretic for resistant hypertension or CHF;

7. Avoid aspirin to reduce risk of occult gastrointestinal (GI) bleeding and anemia

$\mathrm{MAP}=$ Mean arterial pressure.

Benefits of Low-Protein Diet

1. Low Protein diet permits to keep BUN $<50 \mathrm{mg} / \mathrm{dl}$ (asymptomatic state);

2. BUN $>50 \mathrm{mg} / \mathrm{dL}$ is mostly due to unrestricted protein intake, loss of fluid or GI bleeding and gives rise to gastrointestinal symptoms such as nausea, vomiting and loss of appetite, even CHF;

3. A low-protein diet also minimizes metabolic acidosis, hyperkalemia, hyperphosphatemia and hypertension by reducing intake of sulfate, phosphate, potassium and sodium;

4. Metabolic acidosis suppresses albumin synthesis;

5. Low protein intake can slow down the progression of CKD into ESRD.

Hypertension Control

1. Blood pressure (BP) control $(<140 / 80$ to $120-130 / 70 \mathrm{mmHg}$ ) is essential to preserve anatomy and function of the remaining nephrons;

2. Avoid too low BP $(<120 / 70)$, which will reduce renal blood flow in diseased kidneys;

3. A combination of beta blocker (atenolol or metoprolol $50 \mathrm{mg}$ daily) and calcium channel blocker (amlodipine or isradipine 5 - $10 \mathrm{mg}$ once or twice daily) is very effective in keeping BP under control;

4. In resistant cases, chlorthalidone 25 to $50 \mathrm{mg}$ Po daily or bumetanide $2 \mathrm{mg}$ PO daily is additive.

\section{Hyperkalemia and Metabolic Acidosis}

Both are common with use of

a) ACEI/ARB drugs; 
b) NSAID;

c) High protein meal;

d) Eating too many fruits.

Therapy:

a) Sodium bicarbonate: Sodium bicarbonate is the cornerstone of the therapy in CKD at a dose $650 \mathrm{mg}$ tablet three times daily and is generally adequate to keep $\mathrm{CO}_{2}$ near normal.Some patients may experience gastric bloating. Dose doubles or triples if $\mathrm{CO}_{2}$ in renal panel goes below $20 \mathrm{mmol} / \mathrm{L}$;

b) Alternative to sodium bicarbonate: Bicitra ${ }^{\circledR}$ (Shohl's solution), a mixed solution of sodium citrate and citric acid. Sodium Citrate is converted into sodium bicarbonate endogenously. Dose is $10-30 \mathrm{ml}$ three times daily mixed in orange juice for flavor.

Caution: Do not prescribe Bicitra ${ }^{\circledR}$ with aluminum hydroxide gel (phosphate binder). Bicitra may cause excessive aluminum absorption and lead to aluminum toxicity.

\section{Study in Support of Bicarbonate Therapy in CRF}

Bicarbonate supplementation slows progression of CKD and improves nutritional status [6] [26].

Since metabolic acidosis and hyperkalemia are life threatening, prescriptions of sodium bicarbonate $650 \mathrm{mg}$, thru times daily and sodium polystyrene sulfonate (Kayexalate) suspended in sorbitol $(20 \mathrm{ml}-40 \mathrm{ml})$ per day are lifesaving and inexpensive therapies. Current National Kidney Foundation guidelines recommend oral alkali, including $\mathrm{NaHCO}_{3}$ in $\mathrm{CKD}$ patients with serum $\mathrm{CO}_{2}\left(\mathrm{HCO}_{3}\right)$ less than $22 \mathrm{mmol} / \mathrm{L}$. [27] Complications of sodium bicarbonate use is generally none. Possibility of sodium and water retention with increase of BP remains but it is not clinically evident. However, occasional patients complain of belching and abdominal distention.

Sodium polystyrene sulfonate (Kayexalate): It is dispensed in 30\% sorbitol in a dose of $15 \mathrm{~g}$ in $60 \mathrm{ml}$ providing $5 \mathrm{~g}$ in $20 \mathrm{ml}$. The usual dose is $20 \mathrm{ml}$ twice daily. Loose bowel movement or abdominal gas is common but doesn't deter most patients taking it for the benefit. Glucose elevation due to sorbitol may happen. Thus, it is not recommended in diabetes patients with uncontrolled hyperglycemia. Sodium polystyrene sulfonate has a distinct benefit on renal function besides reducing serum K. Here is a small example for that (Table 9).

In those with diabetes, Kayexalate is prescribed suspended in water as shown in the above patient. Hyperkalemia associated with metabolic acidosis can be effectively treated with 9-alpha fludrocortisone (Florinef ${ }^{\mathbb{B}}$ ), an aldosterone analog which enhances excretion of $\mathrm{K}$ and $\mathrm{H} 2$ ions through renal tubules thereby ameliorating hyperkalemia and metabolic acidosis. Florinef also enhances K excretion, though the colon,, thus may restore nomokalemia sooner than kayexalate. However, Florinef through Na retention may give rise to hypertension and CHF. An example of preservation of intact nephrons is shown in Figure 7.

74 y WM 1) Uncontrolled hypertension for years requiring 4 - 5 lines antihypertensive therapy. 2) Atrophic right kidney removed in 2006 for control of BP. 3) No ACEI/ARB Drugs WM = white male.

Although renal function has decreased over the years, the rate of decrease was small. He did not develop ESRD or any complications related to CKD.

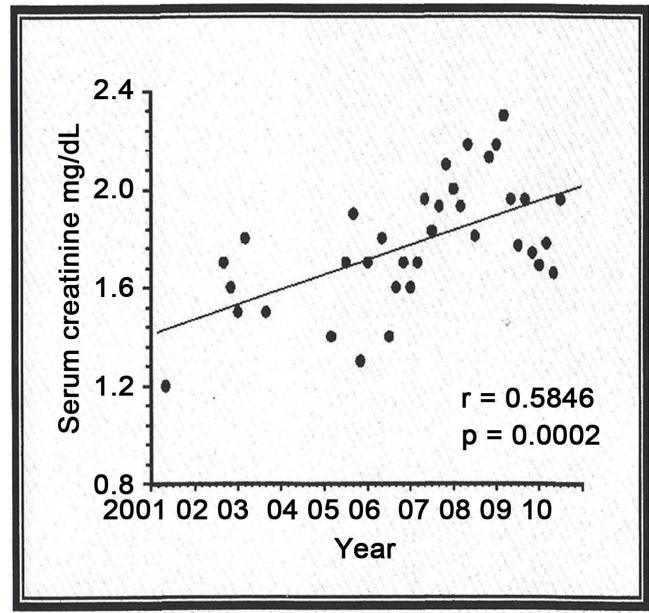

As of July
2012,
BP sitting:
$130 / 70 \mathrm{mmHg}$
Standing:
$120 / 70$
$\mathrm{mmHg}$
Serum
creatinine:
$2.16 \mathrm{mg} / \mathrm{dL}$

Figure 7. Assertion of preservation of intact nephron. 
Table 9. Benefits of sodium polystyrene sulfonate (Kayexalate ${ }^{\mathbb{R}}$ ) on renal function.

69 AAF: CKD Stage 3 due to diabetic nephropathy

June 2, 2010, Hyperkalemia K 5.2 mmol/L

Prescription: Kayexalate $5 \mathrm{~g}$ mixed in water daily $\times 5$ days

$\begin{array}{cccc}2010 & \text { June } 2 & \text { June } 11 & \begin{array}{c}\text { Kayexalate } \\ \text { not suspended in sorbitol } \\ \text { can be constipating }\end{array} \\ \mathrm{Scr}(\mathrm{mg} / \mathrm{dL}) & 62 & 39 & 1.46 \\ \mathrm{eGFR} & 1.86 & 37 & \\ \mathrm{~K}(\mathrm{mmol} / \mathrm{L}) & 28 & 4.1 & \\ & 5.2 & & \end{array}$

\section{Pearl of Wisdom in Caring Patients with CKD}

1. Be kind and compassionate.

2. Give them hope of staying well and not entering into dialysis.

3. Hypertension control is a critical issue in patients with CKD. Control BP with beta blocker, calcium channel blocker, sympathetic inhibitor or a combination of two or 3 drugs of these classes.

4. Refrain in prescribing ACEI/ARB drugs due to commercial bias of renoprotective effect. These drugs will rapidly decrease the remaining kidney function and render the patients symptomatic from metabolic acidosis, hyperkalemia and decreased urine flow as well as rapidly developing anemia.

5. Since sodium and water retention is the main cause of resistant hypertension in CKD, don't hesitate to prescribe chlorthalidone 25 to $50 \mathrm{mg}$ daily or bumetanide $1-2 \mathrm{mg}$ once or twice daily, realizing that diuretic may decrease the kidney function but will minimize metabolic acidosis due to enhanced bicarbonate absorption. Diuretics will also help to control hyperkalemia.

6. Do not coerce the patients to enter into dialysis for the purpose of survival. Survival with dialysis may be a bit longer than conservative management but most of the survival time will be spent in the hospital or in a nursing home [27]. Present the facts and let the patients and their families make the decision.

7. Lastly, it is important to know that renal failure is not a prodrome of dialysis [28].

\section{References}

[1] Chobanian, A.V., Bakris, G.L., Black, H.R., Cushman, W.C., Green, L.A., Izzo Jr., J.L., et al., the National Heart, Lung, and Blood Pressure Coordinating Committee (2003) Seventh Report of the Joint National Committee on Prevention, Detection, Evaluation, and Treatment of High Blood pressure. Hypertension, 42, 1206-1252. http://dx.doi.org/10.1161/01.HYP.0000107251.49515.c2

[2] National Kidney Foundation (2002) K/DOQI Clinical Practice Guidelines for Chronic Kidney Disease: Evaluation, Classification and Satisfaction. American Journal of Kidney Diseases, 39, S1-S266.

[3] Woodhouse, S., Batten Hendrick, H. and Malek, P.A. (2006) The Glomerular Filtration Rate: An Important Test for Diagnosis, Staging, and Treatment of Chronic Kidney Disease. Lab Medicine, 37, 244-246.

[4] Couser, W.G., Remuzzi, G., Medis, S. and Tonelli, M. (2011) The Contribution of Chronic Kidney Disease to the Global Burden of Non-Communicable Diseases. Kidney International, 80, 1258-1270. http://dx.doi.org/10.1038/ki.2011.368

[5] Muntner, P., Anderson, A., Charleston, J., Chen, Z., Ford, V., Makos, G., O’Connor, A., Perumal, K., Rahman, M., Steigerwarlt, S., Teal, V., Townsend, R., Weir, M. and Wright, J.T. (2010) Hypertension Awareness, Treatment and Control in Adults with CKD Results from the Chronic Renal Insufficiency Cohort (CRIC) Study. American Journal of Kidney Diseases, 55, 441-451. http://dx.doi.org/10.1053/j.ajkd.2009.09.014

[6] Loniewski, I. and Wesson, D.E. (2014) Bicarbonate Therapy for Prevention of Chronic Kidney Disease Progression. Kidney International, 85, 529-535. http://dx.doi.org/10.1038/ki.2013.401

[7] Rajapurkar, M.M., John, G.T., Kirpalani, A.L., Abraham, G., Agarwal, S.K., Almeida, A.F., Gang, S., Gupta, A., Modi, G., Pahari, D., Pisharody, R., Prakash, J., Raman, A., Rana, D.S., Sharma, R.K., Sahoo, R.N., Sakhuja, V., Tatapudi, 
R.R. and Jha, V. (2012) What Do We Know about Chronic Kidney Disease in India: First Report of the Indian CKD Registry. BMC Nephrology, 13, 10. (Open Access) http://dx.doi.org/10.1186/1471-2369-13-10

[8] Singh, A.K., Farag, Y.M.K., Mittal, B.V., Subramanian, K.K., Reddy, S.R.K., Acharya, V.N., Almeida, A.F., Channakeshavamurthy, A., Ballal, H.S.P.G., Issacs, R., Jasuja, S., Kirpalani, A.L., Kher, V., Modi, G.L., Mainan, G., Prakash, J., Rana, D.S., Sreedhara, R., Sinha, D.K.V.S.B., Sunder, S., Sharma, R.K., Seetharam, S., Raju, T.R. and Rajapurkar, M. (2013) Epidemiology and Risk Factors of Chronic Kidney Disease in India-Results from Seed (Screening and Early Evaluation of Kidney Disease) Study. BMC Nephrology, 14, 114. (Open Access)

[9] Harris, M.I. (1993) Undiagnosed NIDDM: Clinical and Public Health Issues. Diabetes Care, 16, $642-652$. http://dx.doi.org/10.2337/diacare.16.4.642

[10] The DECODE Study Group and on Behalf of the European Diabetes Epidemiology Group (2003) Is the Current Definition of Diabetes Relevant to Mortality Risk from All Causes and Cardiovascular and Non-Cardiovascular Disease? Diabetes Care, 26, 688-696. http://dx.doi.org/10.2337/diacare.26.3.688

[11] Lewis, E.J., Hunsicker, L.G., Bain, R.P. and Rohde, R.D. (1993) The Effect of Anigiotensin Converting Enzyme Inhibitions on Diabetic Nephropathy. New England Journal of Medicine, 329, 1456-1462. http://dx.doi.org/10.1056/NEJM199311113292004

[12] Mandal, A.K., Hiebert, L.M. and Khamis, H. (2011) dGlucose Is Linked to Renal Function Changes in Diabetes. Diabetes Research and Clinical Practice, 91, 190-194. http://dx.doi.org/10.1016/j.diabres.2010.11.013

[13] Mandal, A.K. and Hiebert, L.M. (2012) Control of Postprandial Hyperglycemia: How Important Is It in the Prevention of Diabetic Complication. Current Trends in Endocrinology, 6, 53-63.

[14] Patel, V.D., Hernandez, A.F., Liang, L., Peterson, E.D., LaBresh, K.A., Yancy, C.W., Albert, N.M., Ellrodt, G. and Fonarow, G.C. (2008) Quality of Care and Outcomes among Patients with Heart Failure and Chronic Kidney Disease: A Get with the Guidelines-Heart Failure Program Study. American Heart Journal, 156, 674-681. http://dx.doi.org/10.1016/j.ahj.2008.05.028

[15] Packer, M., Lee, W.H., Medina, N., Yushak, M. and Kessler, P.D. (1987) Functional Renal Insufficiency during Long-Term Therapy with Captopril and Enalapril in Severe Chronic Heart Failure. Annals of Internal Medicine, 106, 346-354. http://dx.doi.org/10.7326/0003-4819-106-3-346

[16] Mandal, A.K. (2014) Pathophysiology, Prevention and Treatment of Severe Congestive Heart Failure Associated with Progressive Renal Failure. Journal of Cardiology and Therapy, 1, 41-45.

[17] Mandal, A.K. (2014) Frequent Office Visit of Patients with Chronic Kidney Disease: Is a Prelude to Prevention of Dialysis. World Journal of Nephrology, 3, 1-5.

[18] Brown, E.A. (2012) What Can We Do to Improve Quality of Life for the Elderly Chronic Kidney Disease Patient. Aging Health, 8, 519-524. http://dx.doi.org/10.2217/ahe.12.49

[19] Lea, J., Green, T., Hebert, L., Lipkowitz, M., Massry, S., Middleton, J., Rostand, S.G., Miller, E., Smith, W. and Bakris, G.L. (2005) The Relationship between Magnitude of Proteinuria Reduction and Risk of End-Stage Renal Disease: Results of the African American Study of Kidney Disease and Hypertension. Archives of Internal Medicine, 165, 947-953. http://dx.doi.org/10.1001/archinte.165.8.947

[20] Remuzzi, G., Chiurchiu, C. and Ruggenenti, P. (2004) Proteinuria Predicting Outcome in Renal Disease: Nondiabetic Nephropathies (REIN). Kidney International, 92, S90-S96. http://dx.doi.org/10.1111/j.1523-1755.2004.09221.x

[21] Hovind, P., Rossing, P., Tarnow, L., Toft, H., Parving, J. and Parving, H.H. (2001) Remission of Nephrotic Range Albuminuria in Type 1 Diabetic Patients. Diabetes Care, 24, 1972-1977. http://dx.doi.org/10.2337/diacare.24.11.1972

[22] Lewis, J. (2007) Treating Diabetic Nephropathy: Unfinished Success Is Not Failure. Clinical Journal of the American Society of Nephrology, 2, 407-409. http://dx.doi.org/10.2215/CJN.01170307

[23] Ficociello, L.H., Perkins, B.A., Silva, K.H., Finkelstein, D.M., Ignatowska-Switalska, H., Gaciong, Z., Cupples, L.A., Aschengrau, A., Warram, J.H. and Kroleski, A.S. (2007) Determinants of Progression from Microalbuminuria to Proteinuria in Patients Who Have Type 1 Diabetes and Are Treated with Angiotensin-Converting Enzyme Inhibitors. Clinical Journal of the American Society of Nephrology, 2, 461-469. http://dx.doi.org/10.2215/CJN.03691106

[24] Warram, J.H., Scott, L.J., Hanna, L.S., Wantman, M., Cohen, S.E., Laffel, L.M., Ryan, L. and Krolewski, A.S. (2000) Progression of Microalbuminuria to Proteinuria in Type 1 Diabetes: Nonlinear Relationship with Hyperglycemia. Diabetes, 49, 94-100. http://dx.doi.org/10.2337/diabetes.49.1.94

[25] Himmelfarb, J., Berns, A., Szczech, L. and Wesson, D. (2007) Cost, Quality, and Value: The Changing Political Economy of Dialysis Care. Journal of the American Society of Nephrology, 18, 2021-2027. http://dx.doi.org/10.1681/ASN.2007020152

[26] de Brito-Ashurst, I., Varagunan, M., Raftery, M.J. and Yaqoob, M. (2009) Bicarbonate Supplementation Slows Progression of CKD and Improves Nutritional Status. Journal of the American Society of Nephrology, 20, 2075-2084. http://dx.doi.org/10.1681/ASN.2008111205 
[27] Berger, J.R. and Hedayati, S.S. (2012) Renal Replacement Therapy in Elderly Population. Clinical Journal of the American Society of Nephrology, 7, 1039-1046. http://dx.doi.org/10.2215/CJN.10411011

[28] Mandal, A.K. (2013) Renal Failure Is Not a Prodrome of Dialysis. International Journal of Medical Sciences and Biotechnology, 1, 1-14. 